\title{
Health Literacy among Older Adults during COVID-19 Pandemic
}

\author{
Rujittika Mungmunpuntipantip ${ }^{1}$, Viroj Wiwanitkit ${ }^{2, *}$ \\ ${ }^{1}$ Private Academic Consultant, Bangkok, Thailand \\ ${ }^{2}$ Dr D Y Patil University, Pune, India
}

\section{Dear Editor,}

We would like to share our ideas regarding "Health literacy (HL) among older adults during the coronavirus disease 2019 pandemic: a cross-sectional study in an urban community in Thailand."1) Pechrapa et al. ${ }^{1)}$ presented a case and concluded that "The results of our study provide important information ....community during the COVID-19 pandemic." In this report, the authors conducted a small questionnaire-based survey in a rural district of a country in Indochina. ${ }^{1)}$ They assessed demographic parameters to draw conclusions regarding HL. However, they did not include the complete original questionnaire, and their classification of HL level is unclear.

A recent report from Australia observed a relationship between HL and anti-COVID-19 practices. ${ }^{2)}$ In general, HL among older adults depends on several factors. Older adults in different age groups might have differing abilities to comply with HL assessments. Since it is unclear how HL was classified in the present report, it is difficult to interpret the relationship between observed $\mathrm{HL}$ and practice. Therefore, the further implications on local public health policies might be limited. Additionally, a recent study from Thailand also showed a significant disparity between knowledge, determined by HL, and practice regarding COVID-19.) That study also demonstrated that the knowledge of local Thai older adults was not associated with preventive behaviors against COVID-19,") contrary to reports from Australia, ${ }^{2)}$ and the United States.

These findings might indirectly imply that information from the HL survey might not useful for preventive management for COVID-19 in this setting. In many poor communities, local people might not be able to afford resources for prevention. In addition, insufficient use of preventive equipment, such as facemasks, remains a challenge in many areas. ${ }^{5)}$

Moreover, while knowledge levels may be good, other factors, such as a lack of facilities, may challenge good practices by older adults during pandemics. Developing communities in Indochina face many barriers, including policy barriers and limited local resources, to allow local people to have good health practices despite a good background HL. ${ }^{6}$ In conclusion, $\mathrm{HL}$ assessment is a useful tool for assessing basic health knowledge of older adults, but confounding contexts must be considered regarding their implications in real practice.

\section{ACKNOWLEDGMENTS}

\section{CONFLICT OF INTEREST}

The authors claim no conflicts of interest.

\section{FUNDING}

None.

\section{REFERENCES}

1. Pechrapa K, Yodmai K, Kittipichai W, Charupoonpol P, Suksa$\tan \mathrm{W}$. Health literacy among older adults during the coronavirus disease 2019 pandemic: a cross-sectional study in an urban community in Thailand. Ann Geriatr Med Res 2021;25:309-17.

2. McCaffery KJ, Dodd RH, Cvejic E, Ayrek J, Batcup C, Isautier JM, et al. Health literacy and disparities in COVID-19-related knowledge, attitudes, beliefs and behaviours in Australia. Public Health Res Pract 2020;30:30342012.

3. Vicerra PM. Disparity between knowledge and practice regarding COVID-19 in Thailand: a cross-sectional study of older adults. PLoS One 2021;16:e259154.

4. Wolf MS, Serper M, Opsasnick L, O'Conor RM, Curtis L, Benavente JY, et al. Awareness, attitudes, and actions related to COVID-19 among adults with chronic conditions at the onset of the U.S. outbreak: a cross-sectional survey. Ann Intern Med 2020;173:100-9. 
5. Marson BA, Craxford S, Valdes AM, Ollivere BJ. Are facemasks a priority for all staff in theatre to prevent surgical site infections during shortages of supply? A systematic review and meta-analysis. Surgeon 2021;19:e132-e139.

6. Naing SH, Isaramalai SA, Sukmag P. Policy Literacy, barriers, and gender impact on accessibility to healthcare services under compulsory migrant health insurance among Myanmar migrant workers in Thailand. J Environ Public Health 2020;2020: 8165492 .
Corresponding Author: Rujittika Mungmunpuntipantip, $\mathrm{PhD}$

Private Academic Consultant, Bangkok 104410, Thailand

E-mail: rujittika@gmail.com

ORCID: https://orcid.org/0000-0003-0078-7897

Received: November 15, 2021; Revised: November 19, 2021; Accepted: November 22, 2021

*The author is currently an honorary professor at Dr D Y Patil University. 